\title{
Detecting Representations of Recent and Remote Autobiographical Memories in vmPFC and Hippocampus
}

\author{
Heidi M. Bonnici, ${ }^{1}$ Martin J. Chadwick, ${ }^{1}$ Antoine Lutti, ${ }^{1}$ Demis Hassabis, ${ }^{2}$ Nikolaus Weiskopf, ${ }^{1}$ and Eleanor A. Maguire \\ ${ }^{1}$ Wellcome Trust Centre for Neuroimaging, Institute of Neurology, University College London, London, WC1N 3BG, United Kingdom, and ${ }^{2}$ Gatsby \\ Computational Neuroscience Unit, University College London, London, WC1N 3AR, United Kingdom
}

\begin{abstract}
How autobiographical memories are represented in the human brain and whether this changes with time are questions central to memory neuroscience. Two regions in particular have been consistently implicated, the ventromedial prefrontal cortex (vmPFC) and the hippocampus, although their precise contributions are still contested. The key question in this debate, when reduced to its simplest form, concerns where information about specific autobiographical memories is located. Here, we availed ourselves of the opportunity afforded by multivoxel pattern analysis to provide an alternative to conventional neuropsychological and fMRI approaches, by detecting representations of individual autobiographical memories in patterns of fMRI activity. We examined whether information about specific recent (two weeks old) and remote (10 years old) autobiographical memories was represented in vmPFC and hippocampus, and other medial temporal and neocortical regions. vmPFC contained information about recent and remote autobiographical memories, although remote memories were more readily detected there, indicating that consolidation or a change of some kind had occurred. Information about both types of memory was also present in the hippocampus, suggesting it plays a role in the retrieval of vivid autobiographical memories regardless of remoteness. Interestingly, we also found that while recent and remote memories were both represented within anterior and posterior hippocampus, the latter nevertheless contained more information about remote memories. Thus, like vmPFC, the hippocampus too respected the distinction between recent and remote memories. Overall, these findings clarify and extend our view of vmPFC and hippocampus while also informing systems-level consolidation and providing clear targets for future studies.
\end{abstract}

\section{Introduction}

Understanding the neuronal evolution of autobiographical memories and the mechanisms involved in facilitating the vivid reexperiencing of episodes from decades earlier is at the heart of memory neuroscience. Consolidation of memories undoubtedly occurs rapidly at the synaptic level (Dudai, 2004). By contrast, systems-level consolidation (Dudai, 2004, 2012), and how the neural instantiation of autobiographical memories might change over longer timescales, remains uncertain. Much of the focus in this field has been on the brain areas that are implicated. In the main, current theories generally agree that the neocortex comes to play a greater role in supporting autobiographical memories over time (Marr, 1971; Teyler and DiScenna, 1985; Squire, 1992; Nadel and Moscovitch, 1997; Winocur and Moscovitch, 2011; Nadel et al., 2012). The precise areas of neocortex that may be involved are often not specified, although the ventromedial prefrontal cortex (vmPFC) in particular has been highlighted as po-

\footnotetext{
Received May 23, 2012; revised Sept. 19, 2012; accepted Sept. 28, 2012.

Author contributions: H.M.B., M.J.C., D.H., and E.A.M. designed research; H.M.B., A.L., and E.A.M. performed research; N.W. contributed unpublished reagents/analytic tools; H.M.B., M.J.C., and E.A.M. analyzed data; H.M.B. and E.A.M. wrote the paper.

This work was funded by the Wellcome Trust. We thank S. Mullally, T. FitzGerald, and D. Passingham for helpful discussions, and J. Glensman and K. Johannesson for imaging support.

The authors declare no competing financial interests.

Correspondence should be addressed to either Heidi M. Bonnici or Eleanor A. Maguire, Wellcome Trust Centre for Neuroimaging, Institute of Neurology, University College London, 12 Queen Square, London, WC1N3BG, UK, E-mail: e.maguire@ucl.ac.uk or h.bonnici@ucl.ac.uk.

DOI:10.1523/JNEUROSCI.2475-12.2012

Copyright $\odot 2012$ the authors $\quad 0270-6474 / 12 / 3216982-10 \$ 15.00 / 0$
}

tentially influential for memory consolidation (Bontempi et al., 1999; Frankland and Bontempi, 2005) (for review, see Nieuwenhuis and Takashima, 2011).

There is also agreement that autobiographical memories depend on the hippocampus during initial encoding (Scoville and Milner, 1957). However, its role in supporting autobiographical memories when they are more remote is contentious. The standard model of consolidation argues that declarative (including autobiographical) memories become less dependent on the hippocampus, eventually eschewing the need for its involvement during retrieval (Marr, 1971; Teyler and DiScenna, 1985; Squire, 1992). Alternative theories (Multiple Trace Theory, Scene Construction Theory) propose instead that the hippocampus is necessary for retrieving vivid autobiographical memories in perpetuity (Nadel and Moscovitch, 1997; Winocur and Moscovitch, 2011; Hassabis and Maguire, 2007, 2009). Differential findings across studies of patients with hippocampal lesions and amnesia (for review, see Winocur and Moscovitch, 2011) and opposing results from fMRI experiments (Maguire et al., 2001; Ryan et al., 2001; Maguire and Frith, 2003; Gilboa et al., 2004; Piolino et al., 2004; Rekkas and Constable, 2005; Steinvorth et al., 2006; Viard et al., 2007, Watanabe et al., 2012; but see Niki and Luo, 2002; Piefke at al., 2003) contribute to the stalemate.

While acknowledging the importance of brain networks (Svoboda et al., 2006) and connectivity (Maguire et al., 2000a; Söderlund et al., 2012) in autobiographical memory retrieval, nevertheless, the key question in this debate, when reduced to its simplest form, concerns where information about specific auto- 
Table 1. Memory characteristics

\begin{tabular}{|c|c|c|c|c|}
\hline \multirow[b]{2}{*}{ Variable } & \multirow{2}{*}{$\begin{array}{l}\text { Recent } \\
\text { mean (SD) }\end{array}$} & \multirow{2}{*}{$\begin{array}{l}\text { Remote } \\
\text { mean (SD) }\end{array}$} & \multicolumn{2}{|c|}{$\begin{array}{l}\text { Recent versus } \\
\text { remote }\end{array}$} \\
\hline & & & $t$ value & $p$ valu \\
\hline Recall frequency before the interview & $1.64(0.611)$ & $1.83(0.415)$ & 1.258 & 0.235 \\
\hline $\begin{array}{l}\text { Recall frequency between the interview } \\
\text { and scan }\end{array}$ & $1.08(0.208)$ & $1.03(0.095)$ & 1.483 & 0.166 \\
\hline Vividness & $4.58(0.352)$ & $4.39(0.372)$ & 1.549 & 0.15 \\
\hline Level of detail & $4.47(0.414)$ & $4.14(0.576)$ & 1.7 & 0.117 \\
\hline $1 s t / 3 r d$ person perspective & $1(0)$ & $1.08(0.149)$ & 1.915 & 0.082 \\
\hline Emotional valence & $3.17(0.301)$ & $3.14(0.172)$ & 0.372 & 0.717 \\
\hline Active/static event & $1(0)$ & $1.03(0.095)$ & 1 & 0.339 \\
\hline Consistency of recall trial-to-trial & $4.83(0.225)$ & $4.72(0.372)$ & 1.317 & 0.215 \\
\hline
\end{tabular}

Ratings were on a scale of 1 to 5 , where 1 was the minimum and 5 the maximum. For emotional valence: $1,2=$ negative, $3=$ neutral, $4,5=$ positive. For 1 st $/ 3$ rd person perspective: $1=1$ st person, $2=3$ rd person. For active/static event: $1=$ active, 2 = static.

biographical memories is located. This issue cannot be addressed easily with conventional neuropsychological and fMRI approaches. By contrast, by using multivoxel pattern analysis (MVPA) (Haynes and Rees, 2006; Norman et al., 2006) it is possible to "decode" individual memory representations from patterns of fMRI BOLD activity across voxels (Chadwick et al., 2010, 2011, 2012; Rissman and Wagner, 2012). To date, MVPA has not been applied to the study of autobiographical memories, despite the leverage it could offer on theoretical debates about consolidation (Chadwick et al., 2012). Therefore, in this study we used high-resolution fMRI (Carr et al., 2010) and MVPA to ask whether information about specific recent and remote autobiographical memories was detectable in vmPFC and hippocampus (and in other medial temporal and neocortical regions); and furthermore, if detectability of memory representations within a region was influenced by remoteness.

\section{Materials and Methods}

\section{Participants}

Twelve healthy right-handed, university-educated, participants ( 9 female) took part in the experiment (mean age 27.5 years, SD 3.2, range 22-33). All had normal or corrected-to-normal vision and gave informed written consent to participation in accordance with the local research ethics committee.

\section{Memories}

The interview technique used in this experiment was a standard method used in numerous previous studies (Maguire et al., 2001; Addis et al., 2004a, b; Summerfield et al., 2009). One week before scanning, participants were asked to recollect events that happened from a particular time frame (two weeks ago or 10 years ago). An example of the type of memory that was required was provided and it was emphasized that very private or emotional memories, events that happened repeatedly or were very similar to other events, or memories related to public events were not suitable. The memories should unfold in an event-like way, and be very clear and vivid such that when recollecting the memory they felt as if they were reexperiencing the event. Participants were also instructed that they should provide memories that they had rarely thought about since the time the original event had occurred. General probes were given by the interviewer when required (e.g., "what else can you tell me about this event"). Notes were taken about each memory by the interviewer. Having described a memory, participants then rated each memory along a range of parameters (Table 1).

During the interview, participants generally recalled 6-7 memories from each time period. Based on the ratings for these memories, six memories (three recent and three remote) were then selected from this memory pool to be used in the scan experiment. Several criteria guided the selection of the memories for inclusion. Only those memories that had very high ratings for variables such as vividness (Table 1 ), and that were matched to each other both within the recent and remote sets and between the two sets across all the variables, were included. In addition, the experienced interviewer had to be satisfied that the memories were richly detailed and vivid, and seemed to be genuinely reexperienced by the participant. The recent memories were on average 13.3 (SD 2.7) days old, while the remote memories were on average 10.4 (SD 0.57) years old (note that memories were 7 days older when scanned a week later). Mean ratings for these memories are shown in Table 1, and confirm that the memories were vivid and could be recalled consistently on repeated occasions. Of note, the memories were also rated as not having been recalled very much since the initial occurrence of the event. Statistical comparisons (two tailed $t$ tests) between recent and remote memories (also reported in Table 1) showed there were no significant differences between the two types of memory for any of the variables.

The interview material was subjected to a careful review to look for clues that might betray differences between the recent and remote memories used in the scanning experiment, but nothing was found. In addition, the memories were coded for the number of overlapping events, locations and people, in case any biases were present: means for recent memories-events: 0 ; locations: 0 ; people: 0.4 ; means for remote memories-events: 0; locations: 0; people: 0.5 . It is clear that the amount of intermemory similarity was very low and did not differ between the recent and remote memories.

Overall, therefore, the recent and remote memories were closely matched, an important prerequisite for this study to rule out differences in these basic variables as driving differential effects that might be detected in the fMRI analyses.

\section{Procedure}

On the day of scanning participants were first asked how often they had thought about the memories since the session a week earlier, and their ratings confirmed they had hardly given them any thought (Table 1). They were then trained to recall each memory within a $12 \mathrm{~s}$ recall period after viewing a word cue (this timing was chosen following pilot testing). There were six training trials per memory. Participants were encouraged to recall a memory as vividly as possible and to maintain the quality and consistency of this recall for the duration of the $12 \mathrm{~s}$ trial, and on each subsequent recall trial for this memory.

During scanning, participants recalled each memory 14 times ( 14 trials for each of 6 memories $=84$ trials) in a pseudo-random order, while ensuring that the same memory was not repeated twice or more in a row. On each trial, a verbal cue was presented that indicated which of the six memories a participant was required to recall (Fig. 1). Following this, an instruction appeared on the screen indicating that participants should close their eyes and vividly recall the cued memory. Participants were instructed not to begin the recall process until this instruction appeared, and were trained on this procedure in the prescan session. After $12 \mathrm{~s}$, an auditory tone sounded signaling they should open their eyes. The participant was then required to provide ratings about the preceding recall trial using a five-key button-box. First, they rated how vivid the memory was in the preceding recall trial (on a scale of $1-5$, where 1 was not vivid at all, and 5 was very vivid). Second, they rated how consistently they had recalled it relative to the original event (where 1 was not consistent at all, and 5 was very consistent). These ratings were used to select only the most vivid (ratings of 4 or 5) and most consistently recalled (ratings of 4 or 5) memories for inclusion in the MVPA analyses, ensuring that we captured genuine reexperiencing. When trials that were not sufficiently vivid or consistent were excluded, this resulted in on average 11.58 (SD 0.30) trials for each of the three recent memories and on average 10.14 (SD 0.89) for each of the three remote memories, with a mean of 63 (33 recent and 30 remote) trials in total per participant that were entered into the MVPA analysis.

After scanning, participants rated on a five-point scale the effort required to recall the memories, where 1 was very easy to recall, and 5 was very difficult to recall. Both recent (mean 1.25, SD 0.32) and remote $(1.58, \mathrm{SD} 0.54)$ memories were recalled with ease. They were also asked "Do you feel that repeatedly recalling a memory changed the memory in any way?," where 1 was not at all, and 5 was very much. Participants indicated that the memories were hardly changed by multiple repetitions (2.08, SD 0.79). 


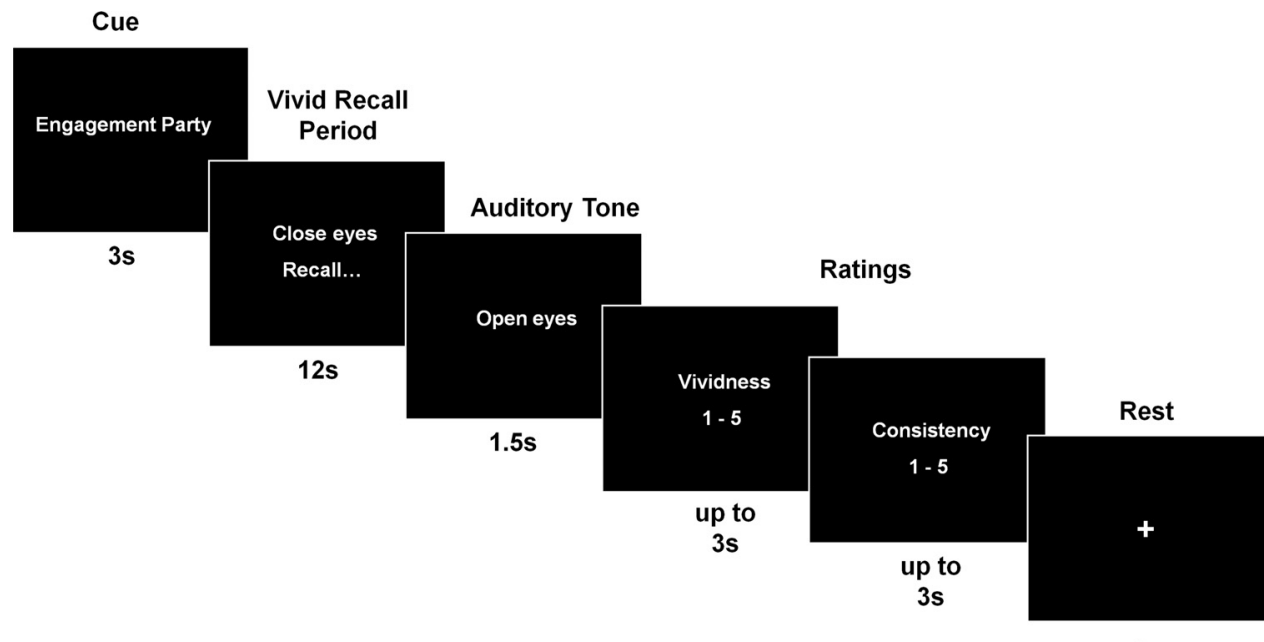

$4 s$

Figure 1. Example timeline from a trial during scanning. On each trial, participants saw a cue telling them which memory to recall. They then closed their eyes and proceeded to recall the memory as vividly as possible. After $12 \mathrm{~s}$ an auditory tone sounded signaling they should open their eyes, and they then made ratings of how vividly the memory had been recalled and also how consistently they had recalled it relative to the original event.

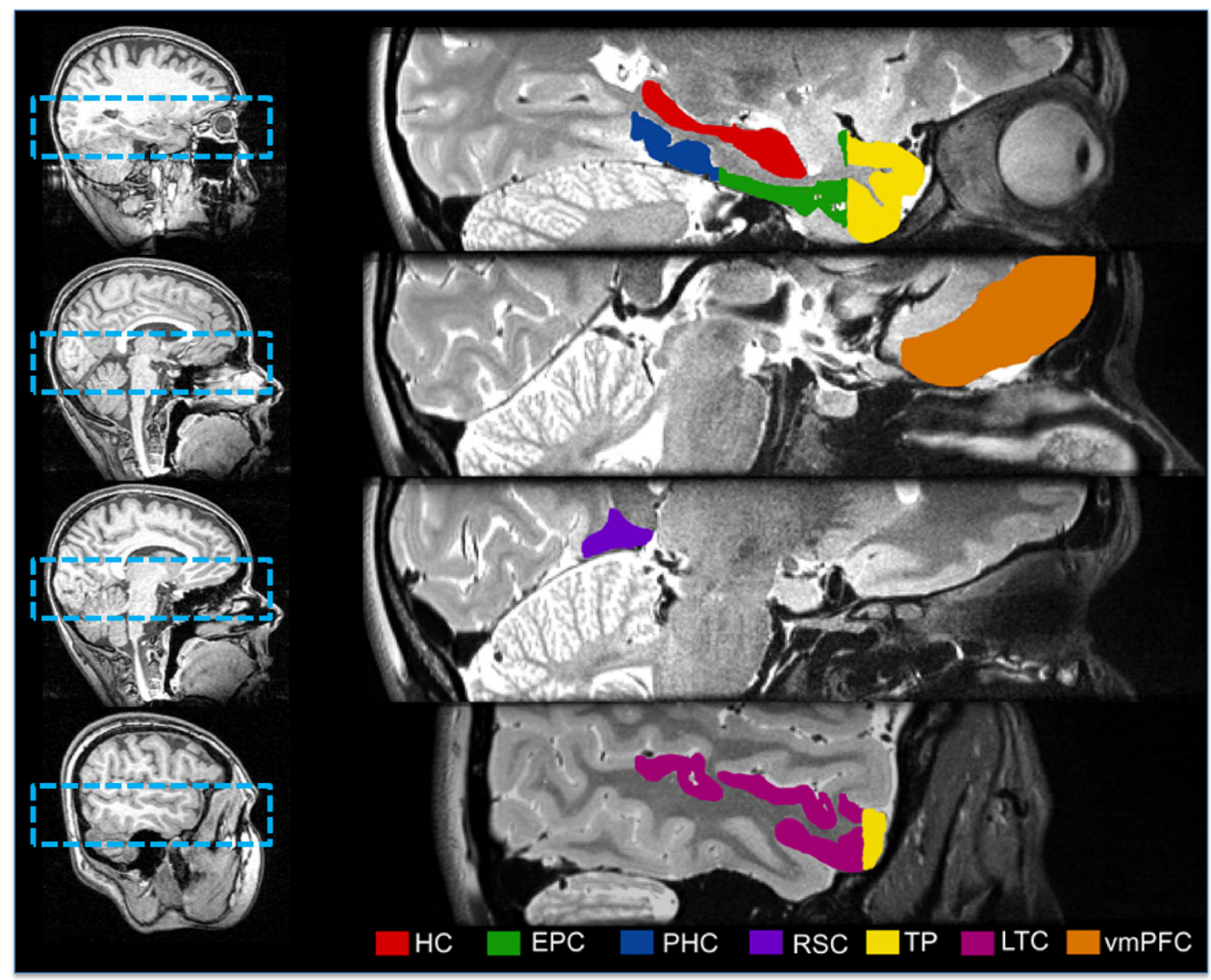

Figure 2. The brain regions examined. High resolution functional ( $1.5 \mathrm{~mm}$ isotropic voxels) and structural ( $0.5 \mathrm{~mm}$ isotropic voxels; right column) MRI scans were acquired in a limited volume (left column; see also Materials and Methods). The following regions were delineated bilaterally: HC, EPC, PHC, RSC (BA 29, 30), TP, LTC (middle temporal gyrus), and vmPFC.

\section{Functional scanning}

Using high-resolution fMRI, we acquired data in a limited volume (Fig. 2). This included our two key regions of interest (ROIs), the vmPFC and hippocampus. In addition, within this volume we were also able to examine other areas known to be involved in autobiographical memory retrieval (Svoboda et al., 2006), entorhinal/perirhinal and posterior parahippocampal cortices, as well as the retrosplenial cortex, the temporal pole, and lateral temporal cortex. A 3T Magnetom Allegra head only MRI scanner (Siemens Healthcare) operated with the standard transmit-receive head coil was used to acquire the functional data with a $\mathrm{T} 2{ }^{*}$ weighted single-shot echo-planar imaging (EPI) sequence in a single session [in-plane resolution $=1.5 \times 1.5 \mathrm{~mm}^{2} ;$ matrix $=128 \times 128$; field of view $=192 \times 192 \mathrm{~mm}^{2} ; 35$ slices acquired in interleaved order; slice thickness $=1.5 \mathrm{~mm}$ with no gap between slices; echo time $(\mathrm{TE})=30 \mathrm{~ms}$; asymmetric echo shifted forward by 26 phase-encoding (PE) lines; echo spacing $=560 \mu \mathrm{s}$; repetition time $(\mathrm{TR})=3.5 \mathrm{~s}$; flip angle $\left.\alpha=90^{\circ}\right]$. All data were acquired at $0^{\circ}$ angle in the anterior-posterior axis. An isotropic voxel size of $1.5 \times 1.5 \times 1.5 \mathrm{~mm}$ was chosen for an optimal trade-off between BOLD sensitivity and spatial resolution. Furthermore, the isotropic voxel dimension reduced resampling artifacts when applying motion correction. To ensure optimal data quality, images were reconstructed online and underwent online quality assurance (Weiskopf et al., 2007). For distortion 
correction (Hutton et al., 2002), field maps were acquired with the standard manufacturer's double echo gradient echo field map sequence $(\mathrm{TE}=10.0$ and $12.46 \mathrm{~ms}$, TR $1020 \mathrm{~ms}$; matrix size, $64 \times 64)$, using 64 slices covering the whole head (voxel size $3 \times 3 \times 3 \mathrm{~mm}$ ). In addition to the functional scans, a whole brain T1-weighted $3 \mathrm{D}$ FLASH sequence was acquired with a resolution of $1 \times 1 \times 1 \mathrm{~mm}$.

Field inhomogeneities in the human brain can result in local signal loss and reduction in BOLD sensitivity that can be compensated by use of $z$-shim gradients (Deichmann et al., 2003; Weiskopf et al., 2006). However, the choice of an optimal $z$-shim value can be challenging when several brain regions with different field inhomogeneities are involved. Here, we assigned an optimal $z$-shim value to each slice of the encoding volume; accounting for all the ROIs in the study. The resulting set of optimal $z$-shim values was used in all subsequent fMRI runs. To calculate the optimal $z$-shim values, a test scan was acquired on each participant before the fMRI experiment. For this scan, an EPI volume was acquired with $z$-shim values ranging from $-5 \mathrm{mT} / \mathrm{m}^{\star} \mathrm{ms}$ to $4 \mathrm{mT} / \mathrm{m}^{\star} \mathrm{ms}$ in steps of $0.2 \mathrm{mT} / \mathrm{m}^{\star} \mathrm{ms}$. All other acquisition parameters were kept identical to the fMRI acquisitions. ROIs were manually defined for each participant. For each slice of the EPI volume, the signal averaged over all the voxels present in the ROIs was calculated and the optimal $z$-shim value yielding maximum signal was selected. For slices that did not contain any ROI, the optimal $z$-shim value was set to zero. A Butterworth low-pass filter was used (cutoff frequency of 0.3) to smooth the distributions of optimal $z$-shim values to avoid large changes in signal between neighboring slices due to sudden changes in optimal $z$-shim values. Before the main scanning experiment, a baseline session comprised of 100 volumes without $z$-shim manipulation was undertaken. We used this baseline to measure the BOLD signal change when $z$-shim manipulation was used. A signal increase of between 1 and $4 \%$ was noted over all regions. A significant signal increase in temporal poles of $18.25 \%$ (SD 10.22) was also observed. Therefore, the $z$-shim manipulation allowed us to obtain a significant signal increase in the anterior temporal lobes without any signal loss in other regions of interest.

\section{Structural scanning}

High-resolution structural images were acquired on a $3 \mathrm{~T}$ whole-body MRI scanner (Magnetom TIM Trio, Siemens Healthcare) operated with the standard transmit body coil and 32-channel head receive coil. Images were acquired in a limited volume that included the ROIs noted above. A single-slab 3D T2-weighted turbo spin echo sequence with variable flip angles (SPACE) (Mugler et al., 2000) in combination with parallel imaging was used to simultaneously achieve a high image resolution of $\sim 500$ $\mu \mathrm{m}$, high sampling efficiency and short scan time while maintaining a sufficient signal-to-noise ratio (SNR). After excitation of a single axial slab the image was read out with the following parameters: resolution $=$ $0.52 \times 0.52 \times 0.5 \mathrm{~mm}^{3}$, matrix $=384 \times 328$, partitions $=104$, partition thickness $=0.5 \mathrm{~mm}$, partition oversampling $=15.4 \%$, field of view $=200 \times$ $171 \mathrm{~mm}^{2}, \mathrm{TE}=353 \mathrm{~ms}, \mathrm{TR}=3200 \mathrm{~ms}$, GRAPPA $\times 2$ in phase-encoding (PE) direction, bandwidth $=434 \mathrm{~Hz} /$ pixel, echo spacing $=4.98 \mathrm{~ms}$, turbo factor in PE direction $=177$, echo train duration $=881$, averages $=1.9$. For reduction of signal bias due to, for example, spatial variation in coil sensitivity profiles, the images were normalized using a prescan, and a weak intensity filter was applied as implemented by the scanner's manufacturer. To improve the SNR of the anatomical image, four scans were acquired for each participant, coregistered, and averaged.

\section{Delineating regions of interest}

Manual segmentation of brain regions was performed using ITK-SNAP (www.itksnap.org) (Yushkevich et al., 2006) on the averaged T2 highresolution structural images of each participant (Fig. 2). Hippocampal anatomy was identified using the Duvernoy (2005) hippocampus atlas. The entorhinal/perirhinal cortex, parahippocampal cortex, and temporal pole were segmented according to the protocol described by Insausti et al. (1998). Lateral temporal cortex segmentation was guided by the Duvernoy whole brain atlas (Duvernoy and Bourgouin, 1999), and the retrosplenial cortex was defined as BA regions 29 and 30 (Vann et al., 2009). Ventromedial prefrontal cortex was delineated as one region encompassing areas where previous work demonstrated involvement in consolidation (Nieuwenhuis and Takashima, 2011), namely BA 14, BA 25 , ventral parts of areas 24 and 32, the caudal part of area 10, and the medial part of area 11. Intra-rater reliability was calculated using the DICE overlap metric, which produces an overlap measure between 0 and 1 , where 0 signifies no overlap and 1 is a perfect match (Dice, 1945). HMB performed intra-rater reliability with a six-month interval between first and second segmentations. The DICE metric results (collapsed across hemispheres) were as follows: hippocampus (HC) 0.90, entorhinal/ perirhinal cortex (EPC; combined) 0.77 , posterior parahippocampal cortex (PHC) 0.82, retrosplenial cortex (RSC) 0.70 , temporal pole (TP) 0.85 , lateral temporal cortex (LTC) 0.77 , and vmPFC 0.78 . The mean number of $\left(1.5 \mathrm{~mm}^{3}\right)$ voxels in each area was as follows: HC 935.13 (SD 73.51), EPC 1473.25 (SD 174.65), PHC 572.50 (SD 75.75), RSC 529.63 (SD 117.93), TP 2584.79 (SD 536.63), LTC 3597.29 (SD 798.52), and vmPFC 1167.25 (SD 368.96). Segmentation of the hippocampus into its anterior and posterior portions was based on the protocol of Hackert et al. (2002), where the anterior $35 \%$ of the hippocampus was labeled as anterior and the remainder as posterior. The end of the uncus was used to delineate the border between the anterior and posterior hippocampus. Of note, there were no significant correlations between region size and classifier accuracies (recent $r=0.178, p=0.673$; remote $r=0.143 ; p=0.736$ ).

\section{Image preprocessing}

Image preprocessing was performed using SPM8 (http://www.fil.ion.ucl. ac.uk/spm). The first six EPI volumes were discarded to allow for T1 equilibration effects (Frackowiak et al., 2004). The remaining EPI images were then realigned to correct for motion effects, and minimally smoothed with a $3 \mathrm{~mm}$ FWHM Gaussian kernel. A linear detrend was run on the images to remove any noise due to scanner drift (LaConte et al., 2005) using customized Matlab code. Next, the data were convolved with the canonical hemodynamic response function (HRF) to increase the signal-to-noise ratio (Frackowiak et al., 2004). This HRF convolution effectively doubled the natural BOLD signal delay, giving a total delay of $\sim 12 \mathrm{~s}$. To compensate for this delay, all onset times were shifted forward in time by three volumes, yielding the best approximation to the $12 \mathrm{~s}$ delay given a TR of $3.5 \mathrm{~s}$ and rounding to the nearest volume. Analysis focused on the $12 \mathrm{~s}$ periods of vivid recall (Fig. 1), giving a total of four functional volumes per trial. We conducted a standard mass-univariate analysis on the data and, as expected, this did not reveal any significant results [see the review by Chadwick et al. (2012) for more on the differences between univariate and MVPA approaches].

\section{MVPA}

Overview. A support vector machine (SVM) classifier was created for each region of interest. Each classifier was trained on a portion of the fMRI data relating to the three recent memories and then tested on an independent set of instances of these memories. This was also the procedure for remote memories. This resulted in two accuracy results for each brain region, one for the recent memories and one for the remote memories.

Procedure. We used a standard MVPA procedure that has been described in detail previously (Chadwick et al., 2010, 2012; Bonnici et al., 2012). To reprise briefly, the overall classification procedure involved splitting the fMRI data into two segments: a "training" set used to train a classifier with fixed regularization hyperparameter $C=1$, to identify response patterns related to the memories being discriminated, and a "test" set used to independently test the classification performance (Duda et al., 2001), using a 10-fold cross-validation procedure. Before multivariate classification, feature selection (Guyon and Elisseeff, 2003) was performed on the data from the training set [thereby ensuring that this step was fully independent from final classification, which is critical for avoiding "double-dipping" (Kriegeskorte et al., 2009)]. This was conducted using a standard multivariate searchlight strategy within an ROI. For a given voxel, we first defined a small sphere with a radius of three voxels centered on the given voxel (Kriegeskorte et al., 2006; see also Hassabis et al., 2009; Chadwick et al., 2010, 2012; Bonnici et al., 2012). Note that the spheres were restricted so that only voxels falling within the given region of interest were included. Therefore, the shape of the sphere 
and the number of voxels within it varied depending on the proximity to the region of interest's borders. This procedure then allowed the selection of the searchlight voxel set that contained the greatest degree of decoding information within the training dataset. The mean (and SD) number of voxels selected for each region (collapsed across hemisphere) was as follows: recent-HC: 477.99 (125.74); EPC: 694.93 (149.06); PHC: 291.95 (94.22); RSC: 258.40 (80.51); TP: 1082.17 (372.83); LTC: 1668.58 (576.96); vmPFC: 500.52 (205.08); remote-HC: 400.64 (141.33); EPC: 633.31 (148.71); PHC: 276.72 (75.66); RSC: 249.62 (105.97); TP: 1060.81 (296.58); LTC: 1564.79 (417.92); vmPFC: 497.47 (302.60). Using this voxel subset, the SVM classifier was trained to discriminate between, for example, the three recent memories using the "training" image dataset, and tested on the independent "test" dataset. The classification was performed using the LIBSVM implementation (Chang and Lin, 2011).

Standard SVMs are binary classifiers that operate on two-class discrimination problems, whereas our data involved a three-class problem (i.e., three recent memories or three remote memories). The SVM can, however, be arbitrarily extended to work in cases where there are more than two classes. Typically this is done by reducing the single multiclass problem into multiple binary classification problems that can be solved separately and then recombined to provide the final class prediction (Allwein et al., 2000). We used the well established Error Correcting Output Codes approach (Dietterich and Bakiri, 1994) and computing of the Hamming distance (Hamming, 1950) as described in detail previously (Hassabis et al., 2009; Chadwick et al., 2010, 2011).

Information maps. The feature selection procedure implemented here as part of the analysis pipeline selected subsets of voxels that were most likely to carry information about the memories. This means that for each fold of the cross-validation, a different subset of voxels was selected. To visualize the voxels selected during feature selection, an "information map" was created by simply finding all voxel sets that produced abovechance accuracy on that particular cross-validation fold in a particular ROI. These voxel sets were added together to form a single binary mask. To measure the overlap between recent and remote memory information maps for each participant, we used the DICE metric. To test any overlap against chance, we randomly shuffled the positions of the recent and remote maps within an ROI 1000 times, and every time measured the overlap. This provided us with a null distribution of the DICE metric for that region for each participant. We could then test the actual overlap directly against this null distribution using a $t$ test.

\section{Data analysis}

Results for the left and the right hemispheres were highly similar, and therefore the data we report here are collapsed across hemispheres. The classifier accuracy values for each brain region were compared with chance. Given that we were only interested in whether results were significantly above chance, one-tailed $t$ tests were used. Comparisons of classifier accuracy values for recent and remote memories were conducted using repeated-measures ANOVAs and significant results were subsequently interrogated using two-tailed paired $t$ tests. A threshold of $p<0.05$ was used throughout.

\section{Results}

\section{Recent memories}

We first explored whether it was possible to predict which of the three recent memories was being recalled solely from the pattern of activity across voxels. For each brain region of interest a classifier was first trained on a portion of the fMRI data relating to the three recent memories and then tested on an independent set of trials of these memories (see Materials and Methods). If information was present in the patterns of fMRI activity that enabled discrimination between the three memories, then the classifier would produce a classification result significantly above chance (33\%). Classifiers operating on voxels in all seven ROIs were able to distinguish between the three recent autobiographical memories significantly above chance (Fig. 3, blue line): HC: $t=3.463$, $p=0.005$; EPC: $t=3.431, p=0.006$; PHC: $t=3.209, p=0.008$;

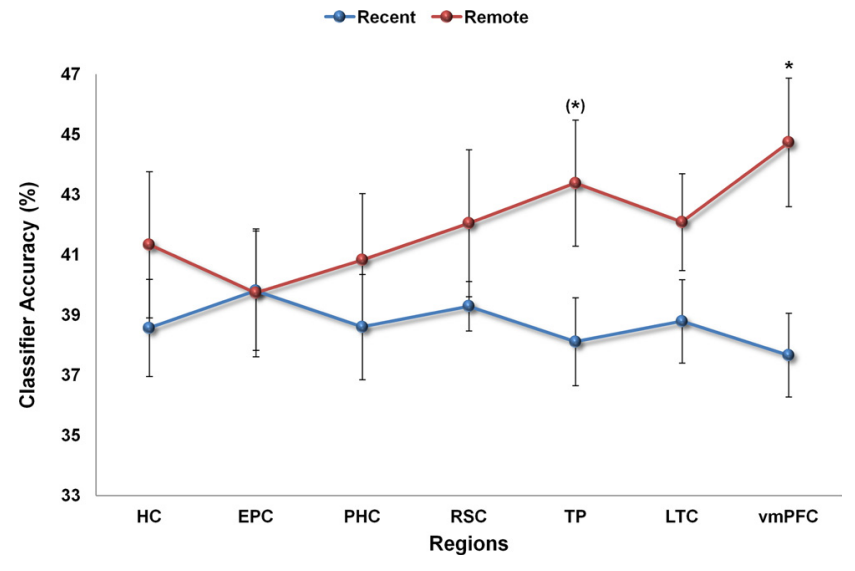

Figure 3. MVPA results for recent and remote autobiographical memories. $\mathrm{HC}, \mathrm{EPC}, \mathrm{PHC}$ RSC, TP, LTC, and vmPFC were examined. Chance $=33 \%$. Medial temporal regions, including the hippocampus, contained similar amounts of information about recent (blue line) and remote (red line) autobiographical memories, while vmPFC contained more information relating to remote memories. ${ }^{*} p<0.05$. The difference between recent and remote memories in TP just failed to reach significance $\left({ }^{*}\right)$. Error bars represent \pm 1 SEM.

RSC: $t=7.639, p=0.001$; TP: $t=3.499, p=0.005$; LTC: $t=4.19$, $p=0.002$; and vmPFC: $t=3.35, p=0.006$.

\section{Remote memories}

Having established that predictable information was present in our regions of interest that enabled above-chance decoding of the recent autobiographical memories, we next considered the three remote memories. As with the recent memories, for each brain region of interest a classifier was trained on a portion of the fMRI data relating to the three remote memories and then tested on an independent set of trials of these memories. Classifiers operating on voxels in the seven ROIs were able to distinguish between the three remote autobiographical memories significantly above chance (Fig. 3, red line): $\mathrm{HC}: t=3.426, p=0.006$; EPC: $t=3.175, p=0.009$; PHC: $t=3.548$, $p=0.005$; RSC: $t=3.713, p=0.003$; TP: $t=4.966, p=0.001$; LTC: $t=5.669, p=0.001$; and vmPFC: $t=5.49, p=0.001)$. Our results, therefore, show that information about the remote memories was represented not only in cortical areas, but also in the medial temporal lobe, including the hippocampus.

\section{Direct comparisons of recent and remote memories}

Comparison of classification accuracies for recent and remote memories using a repeated-measure ANOVA showed no significant differences in medial temporal lobe (MTL) structures (HC, EPC, PHC; $F_{(1,11)}=0.40, p=0.54$; paired $t$ tests: HC: $t=-0.897 ; p=0.389$; EPC: $t=0.023 ; p=0.982$; PHC: $t=-0.877 ; p=0.399)$. However, when cortical areas were considered (RSC, TP, LTC, vmPFC), a significant effect was apparent $\left(F_{(1,11)}=6.79, p=0.038\right)$, with a difference specifically in $\operatorname{vmPFC}(t=-2.833, p=0.016)$ and a marginal effect in TP $(t=-2.029, p=0.066)$, indicating higher classification accuracies for remote memories in these areas. There was no significant difference between recent and remote memories in LTC $(t=-1.457, p=0.173)$ or RSC $(t=-1.179$; $p=0.263)$. This confirms the pattern that is apparent in Figure 3 where medial temporal regions contained similar amounts of information about the recent and remote autobiographical memories. Cortical areas also contained information about recent memories, but information relating to remote memories was in general more readily detectable there.

Of note, we also performed an additional confirmatory analysis to ascertain whether decoding of memory type was possible 

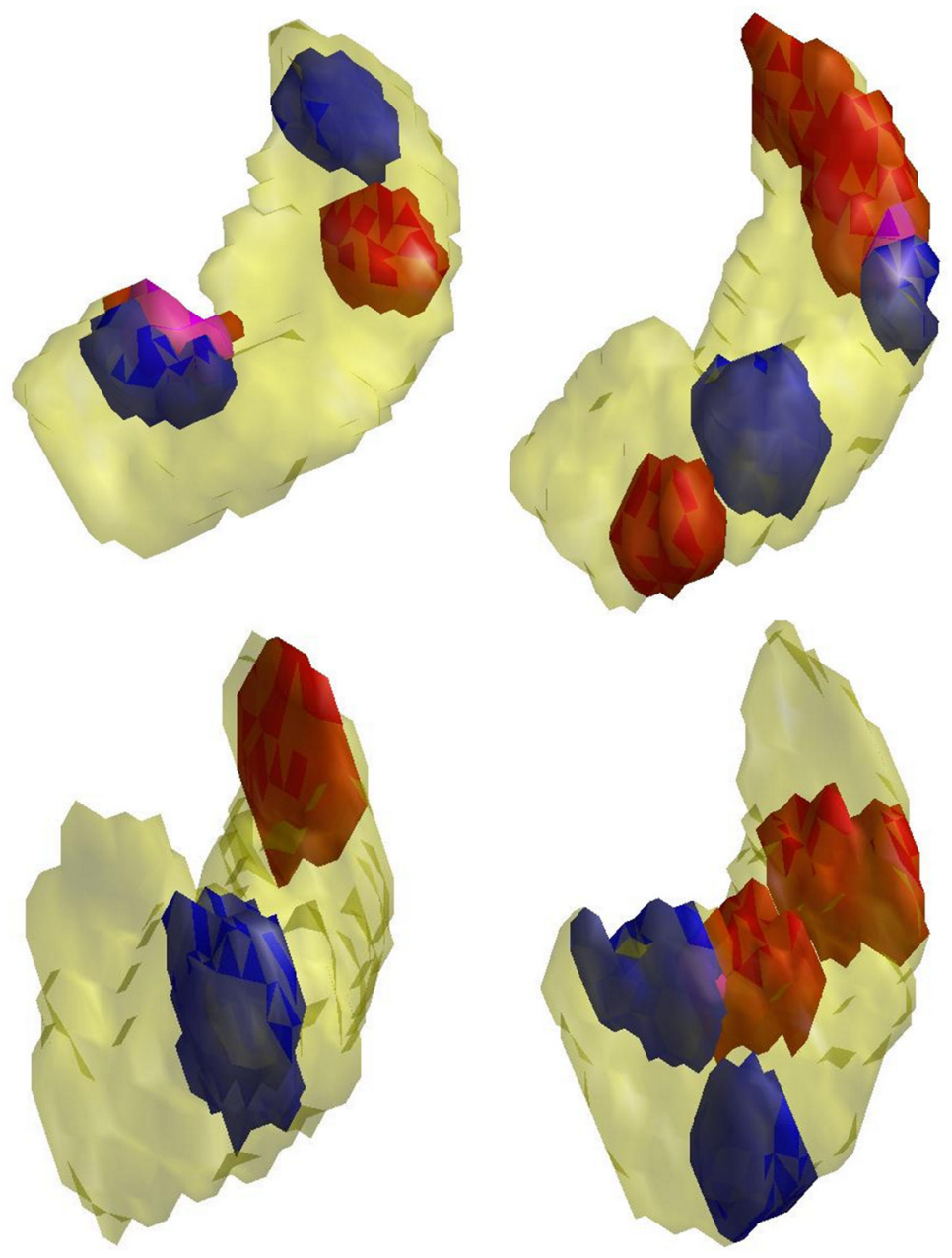

Figure 4. Information maps in the hippocampus. Information maps for recent (shown in blue) and remote (shown in red) autobiographical memories comprised the voxel sets that produced above-chance classification accuracy (see Materials and Methods). The information maps for four example participants are shown superimposed upon 3D images of their right hippocampus. Areas in pink denote where the information maps for recent and remote memories overlapped.

in a way that generalized across the three memories within each memory set. We found that all regions could distinguish between recent and remote events significantly above chance (HC: $t=$ 5.255, $p<0.001$; EPC: $t=6.585, p<0.001$; PHC: $t=4.882, p<$ 0.001 ; RSC: $t=4.794, p<0.001$; TP: $t=7.662, \mathrm{p}=<0.001$; LTC: $t=9.611, p<0.001$; vmPFC: $t=5.274, p<0.001)$.

\section{Spatial distribution of information in vmPFC and hippocampus}

Having established that information about recent and remote autobiographical memories was represented in our key regions of interest, vmPFC and hippocampus, we then proceeded to explore the spatial distribution of recent and remote memory information within each of these regions. Specifically, we wanted to determine whether the voxel patterns (and by inference the underlying neuronal populations) that supported the recent memories overlapped with those supporting the remote memories. Information maps for recent and for remote memories were created from the voxel sets that produced above-chance classification accuracy (see Materials and Methods). To measure the overlap between recent and remote memory information maps, we used the DICE metric. As described earlier, this produces an overlap measure between 0 and 1, where 0 signifies no overlap and 1 is a perfect match. We first examined the vmPFC and found that the DICE metric for overlap between the recent and remote memory information maps was 0.26 . To determine whether this overlap was significantly different from what would be expected by chance, we randomly shuffled the positions of the recent and remote maps within vmPFC 1000 times, and every time measured the overlap. This provided a null distribution of the DICE metric for vmPFC. When the actual score was tested against this null distribution, it was not significantly different from chance $(t=-0.550, p=$ 0.297 ), suggesting that the voxel patterns (and by inference the underlying neuronal populations) that supported the recent memories overlapped with those supporting the remote memories in vmPFC.

By contrast, the DICE metric for the recent and remote memory information maps in the hippocampus, where the null distribution was also determined using the permutation testing procedure, was lower $(0.18)$ than for vmPFC. When this score was tested against the null distribution of the DICE metric that had been calculated for the hippocampus, it was significantly lower than would be expected by chance $(t=-3.201, p=0.004)$, suggesting that the information maps for recent and remote autobiographical memories in the hippocampus did not overlap very much. Visual inspection of the information maps of the participants (see examples in Fig. 4) suggested a separation down the long axis of the hippocampus for recent and remote autobiographical memories. To interrogate this further, the hippocampus was subdivided into anterior and posterior portions (see Materials and Methods), and MVPA analyses were repeated in these portions separately. Abovechance classification was apparent in anterior and posterior hippocampus for recent and remote memories, showing that information about both types of memory was represented in both portions of the hippocampus (recent memories: anterior: $t=$ $2.561, p=0.026$; posterior $t=2.242, p=0.047$; remote memories: anterior: $t=4.665, p=0.001$; posterior: $t=4.225, p=$ 0.001).

The key question in this analysis was whether a systematic bias toward one or other type of memory within the subdivisions existed that would result in a difference in classification performance. This is indeed what we found, with classification accuracies significantly higher in the posterior hippocampus for remote memories compared with recent memories $(t=-2.852, p=$ 0.016; Fig. 5), while in anterior hippocampus, there was no significant difference in classification accuracies for the two types of memory $(t=-0.986, p=0.345)$. Moreover, for recent memories there was no significant difference between classification accuracies in anterior and posterior hippocampus $(t=0.691, p=$ 0.504 ), while for remote memories, as expected given the result above, there was a significant difference, with higher classification accuracy for remote memories in posterior compared with 


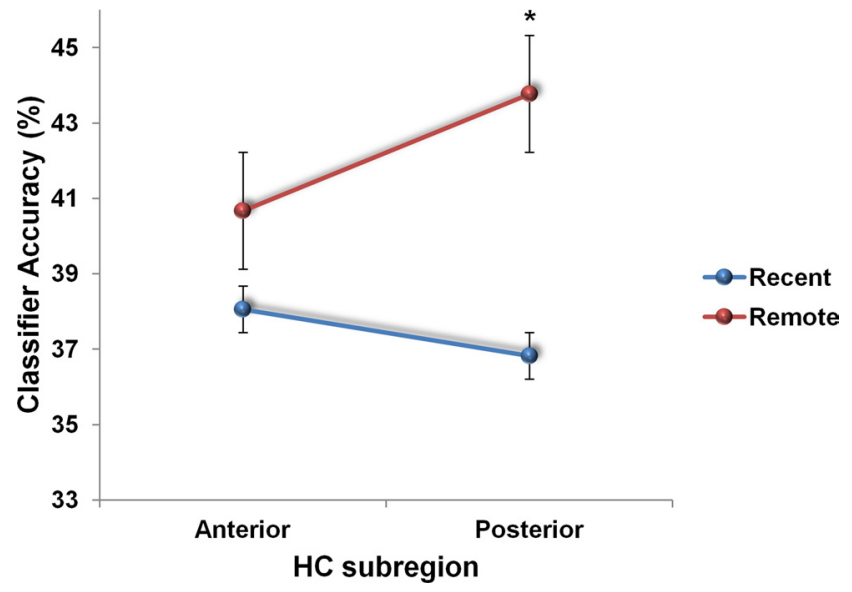

Figure 5. MVPA results for anterior and posterior subregions of $\mathrm{HC}$. Above-chance (chance $=33 \%$ ) classification was apparent in anterior and posterior hippocampus for recent (blue line) and remote (red line) memories, showing that information about both types of memory was represented in both portions of the hippocampus. Nevertheless, classification accuracies were significantly higher in the posterior hippocampus for remote memories compared with recent memories, while in anterior hippocampus there was no such bias. ${ }^{*} p<0.05$. Error bars represent $\pm 1 \mathrm{SEM}$.

anterior hippocampus $(t=-2.237, p=0.047)$. The results of an additional region by memory remoteness interaction analysis accorded well with these results, although just failed to reach significance $\left(F_{(1,11)}=4.305, p=0.062\right)$.

\section{Control analysis and other protocol considerations}

The focus in this study was on brain areas within our partial volume that are known to be involved in autobiographical memory retrieval (Svoboda et al., 2006). However, we also examined accuracy values in control (i.e., not memory-related) cortical regions in the left and right lateral posterior visual cortex. Classifier accuracies for recent and remote memories were at chance, i.e., it was impossible to predict which memories were being recalled from the patterns of activity across voxels there (collapsed across left and right posterior visual cortex; recent: $t=0.096, p=0.463$; remote: $t=0.602, p=0.280$ ). This shows that our classification analysis was not biased toward invariably producing abovechance accuracies.

We also considered whether any other protocol-related factors in addition to the recency/remoteness of autobiographical memories could have influenced our results. For instance, during scanning perhaps participants were recalling the prescan interview where the memories were initially elicited. However, when asked how often they had thought about the memories since the session a week earlier, their ratings confirmed they had hardly given them any thought (see Materials and Methods). Moreover, the interview concerned both the recent and remote memories, and so the differential effects for the two types of memory that we found could not have arisen from this common interview experience.

The scanning paradigm required participants to recall the memories a number of times during scanning, and it could be argued that the memories were reencoded on each trial, which may have polluted the recall effects. As with the interview above, if reencoding did occur, it would presumably have done so for both recent and remote memories, again making the differential results we found difficult to explain. In addition, the nature of MVPA means that classification is only possible if information is shared across training and test trials. Reencoded memories would have been different for each trial leading to chance classification, which was not the case here. On a related theme, it could have been that recalling a remote memory reactivated it, effectively transforming it back into a recent memory. If this was the case, then the prediction would be of no difference between recent and remote memories (if all memories were now essentially recent). However, the differential effects, cortically and within the hippocampus itself, clearly speak against this idea.

Repeatedly recalling the memories may have had other effects. For instance, it may have lessened the true episodic nature of the memories and influenced hippocampal engagement. However, previous studies have shown that hippocampal activation does not diminish as a function of multiple retrievals of autobiographical memories (Nadel et al., 2007; Svoboda and Levine, 2009). Our participants also confirmed that repeated recall did not change the memory (see Materials and Methods), and in fact we only included in the analyses those trials where participants indicated they had recalled the memory with high vividness and consistency, to ensure that we captured genuine reexperiencing. Given that ease of recall and other phenomenological factors were also highly similar across the recent and remote memories (Table 1), neither these, nor the alternatives above, seem to adequately explain our differential findings.

\section{Discussion}

In this study we availed ourselves of the opportunity afforded by MVPA to detect representations of specific autobiographical memories in patterns of fMRI activity. There were three main results; first, we found that information about individual recent (two weeks old) and remote (10 years old) autobiographical memories was present in vmPFC and hippocampus. Indeed, information about both types of memories was detectable in other MTL and cortical areas also, highlighting that rich memories have "traces" across a distributed set of brain regions. Despite this, our second result revealed that information about remote autobiographical memories was more readily detectable in vmPFC and temporal pole compared with recent memories. By contrast, in hippocampus and other MTL structures, information about both types of memories was present to a similar degree. Our third finding uncovered another layer of complexity. When considered as a whole the hippocampus contained representations of recent and remote autobiographical memories in equal measure, but it emerged that the information had a spatial bias, with significantly higher classification accuracy in the posterior hippocampus for remote compared with recent memories. The reverse was true of vmPFC, whereby it contained more detectable information about remote memories compared with recent, but the voxel patterns (and by inference the underlying neuronal populations) that supported the two overlapped.

Considering first the theoretical implications of our findings, in line with extant theories (Marr, 1971; Teyler and DiScenna, 1985; Squire, 1992; Nadel and Moscovitch, 1997; Winocur and Moscovitch, 2011), we found that more information pertaining to remote autobiographical memories was available in neocortical regions compared with recent memories. That is not to say that relatively new memories (two weeks old) were not represented there-they were-but there was less information about them, suggesting that some kind of consolidation or change had occurred. Patterns of activity across voxels in the vmPFC led to the highest decoding accuracies. This area, with dense connections to the hippocampal region, has been linked to memory consolidation in a number of studies (Bontempi et al., 1999; Frankland and Bontempi, 2005; Nieuwenhuis and Takashima, 
2011; see also Goshen et al., 2011; Lesburguères et al., 2011; Tse et al., 2011). Our findings, for the first time at the level of specific memory representations, therefore provide support for neocortical consolidation of autobiographical memories over time.

While broadly agreeing about the nature of neocortical involvement in remote autobiographical memories, theories differ with respect to the hippocampus. If, as proposed by the standard model (Squire, 1992), consolidation eschews the need for hippocampal involvement during retrieval of remote autobiographical memories, then representations of remote memories should not be detectable there. Classifier performance should be at chance for the remote memories, while information relating to recent memories should still be present in the hippocampus. In fact it was possible to predict which of the remote memories was being recalled from patterns of fMRI activity across hippocampal voxels, just as with the recent memories, showing that information about both types of memory was contained there. This result therefore resonates with theories that posit a role for the hippocampus in the vivid recall of autobiographical memories in perpetuity (Nadel and Moscovitch, 1997; Winocur and Moscovitch, 2011; Hassabis and Maguire, 2007, 2009).

We next consider what our results might disclose about mechanisms operating in vmPFC and hippocampus that support the retrieval of recent and remote autobiographical memories. Perhaps vmPFC and hippocampal contributions simply reflect qualitative differences between the recent and remote memories. The two memory types were highly similar on a range of key characteristics that included vividness, ease of recall, and amount of details. Both were vividly reexperienced suggesting that the remote memories were not more semanticized than the recent memories. Therefore, the recent and remote memories, at least as far as it was possible to deduce from the participants' experience of recalling them, were closely matched. Similarly, as outlined (see Results), the differential effects for recent and remote memories cannot easily be explained by arguments relating to reencoding or reactivation.

vmPFC has been linked with many domains including emotional and behavioral regulation, fear extinction, risk-taking, reward, confabulation, and memory (for review, see Nieuwenhuis and Takashima, 2011). In relation to the latter, it has been posited to support strategic retrieval and monitoring (Gilboa et al., 2006), memory suppression (Schnider and Ptak, 1999), and to be an integrator of information that is represented in separate parts of the limbic system and whose role increases over time as that of the hippocampus decreases (Nieuwenhuis and Takashima, 2011). Our data indicate that vmPFC ends up with more information about remote compared with recent autobiographical memories. It is not clear whether this involves a process within vmPFC itself, which is somehow more pertinent for remote memories, or whether vmPFC receives the output of processing from elsewhere to store or on which to perform additional operations. Studies of patients with vmPFC lesions are not helpful in elucidating this issue. While there are a few reports of recent and remote public event memories in patients with vmPFC lesions (Gade and Mortensen, 1990; O’Connor and Lafleche, 2004), systematic comparisons of specifically autobiographical memories that are recent and remote are rare in such cases. One report of damage to vmPFC found associated impairment in recalling autobiographical memories across the lifespan (Bird et al., 2004), while another documented difficulty recalling recent autobiographical memories (Kopelman et al., 1997). Clearly there is a pressing need to explore recent and remote autobiographical memories in patients with vmPFC damage, as its role in such memories and its wider involvement in other aspects of cognition remain to be fully understood. Whatever is occurring in relation to remote autobiographical memories, it does not seem to involve a separate part of vmPFC (the voxel patterns for recent and remote memories overlapped), or to be at the expense of the hippocampus.

Despite information about the two memory types being detectable in the hippocampus, further examination revealed a more complex picture. While recent and remote memories were both represented within anterior and posterior hippocampus, posterior hippocampus nevertheless contained more information about remote memories. Even among theories that propose the hippocampus is necessary for remote memories (Nadel and Moscovitch, 1997; Winocur and Moscovitch, 2011; Hassabis and Maguire, 2007, 2009), this bias was not predicted. Functional differentiation down the long axis of the hippocampus is well documented (Moser and Moser, 1998; Maguire et al., 2000b; Gilboa et al., 2004; Rekkas and Constable, 2005; Fanselow and Dong, 2010). In particular, posterior hippocampus has been associated with spatial processing (Moser and Moser, 1998; Maguire et al., 2000b) and more recently with recollection ability (Poppenk and Moscovitch, 2011). As with vmPFC, therefore, the question arises as to what is going on in posterior hippocampus during the retrieval of autobiographical memories that results in remote memories being better represented there.

We speculate that recent memories are experienced as coherent scenes or events that are temporarily represented in the hippocampus (using anterior and posterior aspects), with neocortical consolidation happening relatively quickly. The constituent elements of autobiographical memories are then the preserve of the neocortex. At retrieval, this piecemeal information is automatically funneled back into the hippocampus (in a process that might involve vmPFC), but to be assembled into a coherent form, this requires a process that takes place in the posterior hippocampus. This, we suggest, is why the remote memories were discernible to a greater degree in posterior hippocampus, because they rely on this process more than recent memories do. We further speculate that the posterior hippocampus may implement the spatial framework into which the elements of a remote memory are reconstructed (Hassabis and Maguire, 2007, 2009), in line with findings from patients with hippocampal damage who have lost the ability to construct spatially coherent scenes (Hassabis et al., 2007; Race et al., 2011; Mullally et al., 2012a).

In conclusion, we provided evidence to suggest that changes occur in autobiographical memory, such that remote memories are more strongly represented in neocortical regions including vmPFC. Recall of rich and vivid autobiographical memories involves the hippocampus regardless of remoteness, but, nevertheless, it too, like the neocortex, respects the distinction between recent and remote autobiographical memories. This pattern of results helps to clarify and extend our view of vmPFC and hippocampus while also informing systems-level consolidation. Furthermore, differential findings relating to recent and remote memories in the hippocampus might help to explain disparate patterns of autobiographical memory across patients with hippocampal lesions (Martin et al., 2011; Mullally et al., 2012b). Clearly, our results raise numerous questions and suggest obvious targets for future investigations. We focused on vivid and easily retrievable memories at two distinct timescales. Studies examining memories that vary in vividness and age could provide a more complete picture of the system at work. Similarly, ours was a cross-sectional design; a longitudinal study tracking specific autobiographical memories over time would be possible 
using MVPA, and could illuminate further the operating mechanisms in vmPFC and hippocampus and the interplay between them.

\section{References}

Addis DR, Moscovitch M, Crawley AP, McAndrews MP (2004a) Recollective qualities modulate hippocampal activation during autobiographical memory retrieval. Hippocampus 14:752-762. CrossRef Medline

Addis DR, McIntosh AR, Moscovitch M, Crawley AP, McAndrews MP (2004b) Characterizing spatial and temporal features of autobiographical memory retrieval networks: a partial least squares approach. Neuroimage 23:1460-1471. CrossRef Medline

Allwein E, Shapire R, Singer Y (2000) Reducing multiclass to binary: a unifying approach for margin classifiers. J Mach Learn Res 1:113-141.

Bird CM, Castelli F, Malik O, Frith U, Husain M (2004) The impact of extensive medial frontal lobe damage on 'Theory of Mind' and cognition. Brain 127:914-928. CrossRef Medline

Bonnici HM, Kumaran D, Chadwick MJ, Weiskopf N, Hassabis D, Maguire EA (2012) Decoding representations of scenes in the medial temporal lobes. Hippocampus 22:1143-1153. CrossRef Medline

Bontempi B, Laurent-Demir C, Destrade C, Jaffard R (1999) Timedependent reorganization of brain circuitry underlying long-term memory storage. Nature 400:671-675. CrossRef Medline

Carr VA, Rissman J, Wagner AD (2010) Imaging the human medial temporal lobe with high-resolution fMRI. Neuron 65:298-308. CrossRef Medline

Chadwick MJ, Hassabis D, Weiskopf N, Maguire EA (2010) Decoding individual episodic memory traces in the human hippocampus. Curr Biol 20:544-547. CrossRef Medline

Chadwick MJ, Hassabis D, Maguire EA (2011) Decoding overlapping memories in the medial temporal lobes using high-resolution fMRI. Learn Mem 18:742-746. CrossRef Medline

Chadwick MJ, Bonnici HM, Maguire EA (2012) Decoding information in the human hippocampus: A user's guide. Neuropsychologia 50:31073121. CrossRef Medline

Chang C, Lin C (2011) LIBSVM: a library for support vector machines. ACM Trans Intell Syst 2:17.

Deichmann R, Gottfried JA, Hutton C, Turner R (2003) Optimized EPI for fMRI studies of the orbitofrontal cortex. Neuroimage 19:430-441. CrossRef Medline

Dice LR (1945) Measures of the amount of ecologic association between species. Ecology 26:297-302. CrossRef

Dietterich TD, Bakiri G (1994) Solving multiclass learning problems via error-correcting output codes. J Artificial Intell Res 2:263-286.

Duda OR, Hart PE, Stork DG (2001) Pattern classification. New York: Wiley.

Dudai Y (2004) The neurobiology of consolidations, or, how stable is the engram? Annu Rev Psychol 55:51-86. CrossRef Medline

Dudai Y (2012) The restless engram: consolidations never end. Annu Rev Neurosci 35:227-247. CrossRef Medline

Duvernoy HM (2005) The human hippocampus, functional anatomy, vascularization and serial sections with MRI, Ed 3. Berlin: Springer.

Duvernoy HM, Bourgouin P (1999) The human brain: surface, threedimensional sectional anatomy with MRI, and blood supply. Berlin: Springer.

Fanselow MS, Dong HW (2010) Are the dorsal and ventral hippocampus functionally distinct structures? Neuron 65:7-19. CrossRef Medline

Frackowiak RSJ, Friston KJ, Frith CD, Dolan RJ, Price CJ, Zeki S, Ashburner JT, Penny WD (2004) Human brain function. New York: Elsevier Academic.

Frankland PW, Bontempi B (2005) The organization of recent and remote memories. Nat Rev Neurosci 6:119-130. CrossRef Medline

Gade A, Mortensen EL (1990) Temporal gradient in the remote memory impairment of amnesic patients with lesions in the basal forebrain. Neuropsychologia 28:985-1001. CrossRef Medline

Gilboa A, Winocur G, Grady CL, Hevenor SJ, Moscovitch M (2004) Remembering our past: functional neuroanatomy of recollection of recent and very remote personal events. Cereb Cortex 14:1214-1225. CrossRef Medline

Gilboa A, Alain C, Stuss DT, Melo B, Miller S, Moscovitch M (2006) Mechanisms of spontaneous confabulations: a strategic retrieval account. Brain 129:1399-1414. CrossRef Medline
Goshen I, Brodsky M, Prakash R, Wallace J, Gradinaru V, Ramakrishnan C, Deisseroth K (2011) Dynamics of retrieval strategies for remote memories. Cell 147:678-689. CrossRef Medline

Guyon I, Elisseeff A (2003) An introduction to variable and feature selection. J Mach Learn Res3:1157-1182.

Hackert VH, den Heijer T, Oudkerk M, Koudstaal PJ, Hofman A, Breteler MM (2002) Hippocampal head size associated with verbal memory performance in nondemented elderly. Neuroimage 17:1365-1372. CrossRef Medline

Hamming RW (1950) Error-detecting and error-correcting. Bell Syst Tech J 29:147-160

Hassabis D, Maguire EA (2007) Deconstructing episodic memory with construction. Trends Cogn Sci 11:299-306. CrossRef Medline

Hassabis D, Maguire EA (2009) The construction system of the brain. Philos Trans R Soc Lond B Biol Sci 364:1263-1271. CrossRef Medline

Hassabis D, Kumaran D, Vann SD, Maguire EA (2007) Patients with hippocampal amnesia cannot imagine new experiences. Proc Natl Acad Sci U S A 104:1726-1731. CrossRef Medline

Hassabis D, Chu C, Rees G, Weiskopf N, Molyneux PD, Maguire EA (2009) Decoding neuronal ensembles in the human hippocampus. Curr Biol 19:546-554. CrossRef Medline

Haynes JD, Rees G (2006) Decoding mental states from brain activity in humans. Nat Rev Neurosci 7:523-534. CrossRef Medline

Hutton C, Bork A, Josephs O, Deichmann R, Ashburner J, Turner R (2002) Image distortion correction in fMRI: A quantitative evaluation. Neuroimage 16:217-240. CrossRef Medline

Insausti R, Juottonen K, Soininen H, Insausti AM, Partanen K, Vainio P, Laakso MP, Pitkänen A (1998) MR volumetric analysis of the human entorhinal, perirhinal, and temporopolar cortices. AJNR 19:659-671. Medline

Kopelman MD, Ng N, Van Den Brouke O (1997) Confabulation extending across episodic, personal, and general semantic memory. Cog Neuropsychol 14:683-712. CrossRef

Kriegeskorte N, Goebel R, Bandettini P (2006) Information-based functional brain mapping. Proc Natl Acad Sci U S A 103:3863-3868. CrossRef Medline

Kriegeskorte N, Simmons WK, Bellgowan PS, Baker CI (2009) Circular analysis in systems neuroscience: the dangers of double dipping. Nat Neurosci 12:535-540. CrossRef Medline

LaConte S, Strother S, Cherkassky V, Anderson J, Hu X (2005) Support vector machines for temporal classification of block design fMRI data. Neuroimage 26:317-329. CrossRef Medline

Lesburguères E, Gobbo OL, Alaux-Cantin S, Hambucken A, Trifilieff P, Bontempi B (2011) Early tagging of cortical networks is required for the formation of enduring associative memory. Science 331:924-928. CrossRef Medline

Maguire EA, Frith CD (2003) Lateral asymmetry in the hippocampal response to the remoteness of autobiographical memories. J Neurosci 23: 5302-5307. Medline

Maguire EA, Mummery CJ, Büchel C (2000a) Patterns of hippocampalcortical interaction dissociate temporal lobe memory subsystems. Hippocampus 10:475-482. CrossRef Medline

Maguire EA, Gadian DG, Johnsrude IS, Good CD, Ashburner J, Frackowiak RS, Frith CD (2000b) Navigation-related structural change in the hippocampi of taxi drivers. Proc Natl Acad Sci U S A 97:4398-4403. CrossRef Medline

Maguire EA, Henson RN, Mummery CJ, Frith CD (2001) Activity in prefrontal cortex, not hippocampus, varies parametrically with the increasing remoteness of memories. Neuroreport 12:441-444. CrossRef Medline

Marr D (1971) Simple memory: a theory for archicortex. Philos Trans R Soc Lond B Biol Sci 262:23-81. CrossRef Medline

Martin VC, Schacter DL, Corballis MC, Addis DR (2011) A role for the hippocampus in encoding simulations of future events. Proc Natl Acad Sci U S A 108:13858-13863. CrossRef Medline

Moser MB, Moser EI (1998) Functional differentiation in the hippocampus. Hippocampus 8:608-619. CrossRef Medline

Mugler JP 3rd, Bao S, Mulkern RV, Guttmann CR, Robertson RL, Jolesz FA, Brookeman JR (2000) Optimized single-slab three-dimensional spinecho MR imaging of the brain. Radiology 216:891-899. Medline

Mullally SL, Intraub H, Maguire EA (2012a) Attenuated boundary extension produces a paradoxical memory advantage in amnesic patients. Curr Biol 22:261-268. CrossRef Medline 
Mullally SL, Hassabis D, Maguire EA (2012b) Scene construction in amnesia: an fMRI study. J Neurosci 32:5646-5653. CrossRef Medline

Nadel L, Moscovitch M (1997) Memory consolidation, retrograde amnesia and the hippocampal complex. Curr Opin Neurobiol 7:217-227. CrossRef Medline

Nadel L, Campbell J, Ryan L (2007) Autobiographical memory retrieval and hippocampal activation as a function of repetition and the passage of time. Neural Plast 2007:90472. Medline

Nadel L, Hupbach A, Gomez R, Newman-Smith K (2012) Memory formation, consolidation and transformation. Neurosci Biobeh Rev 36:1640-1645.

Nieuwenhuis IL, Takashima A (2011) The role of the ventromedial prefrontal cortex in memory consolidation. Behav Brain Res 218:325-334. CrossRef Medline

Niki K, Luo J (2002) An fMRI study on the time-limited role of the medial temporal lobe in long-term topographical autobiographic memory. J Cogn Neurosci 14:500-507. CrossRef Medline

Norman KA, Polyn SM, Detre GJ, Haxby JV (2006) Beyond mind-reading: multi-voxel pattern analysis of fMRI data. Trends Cogn Sci 10:424-430. CrossRef Medline

O'Connor MG, Lafleche GM (2004) Retrograde amneisa in patients with ruture and surgical repair of antioer communicating artery aneurysms. J Int Neurpsychol Soc 10:221-229.

Piefke M, Weiss PH, Zilles K, Markowitsch HJ, Fink GR (2003) Differential remoteness and emotional tone modulate the neural correlates of autobiographical memory. Brain 126:650-668. CrossRef Medline

Piolino P, Giffard-Quillon G, Desgranges B, Chételat G, Baron JC, Eustache F (2004) Re-experiencing old memories via hippocampus: a PET study of autobiographical memory. Neuroimage 22:1371-1383. CrossRef Medline

Poppenk J, Moscovitch M (2011) A hippocampal marker of recollection memory ability among healthy young adults: contributions of posterior and anterior segments. Neuron 72:931-937. CrossRef Medline

Race E, Keane MM, Verfaellie M (2011) Medial temporal lobe damage causes deficits in episodic memory and episodic future thinking not attributable to deficits in narrative construction. J Neurosci 31:10262-10269. CrossRef Medline

Rekkas PV, Constable RT (2005) Evidence that autobiographic memory retrieval does not become independent of the hippocampus: an fMRI study contrasting very recent with remote events. J Cogn Neurosci 17:1950-1961. CrossRef Medline

Rissman J, Wagner AD (2012) Distributed representations in memory: Insights from functional brain imaging. Annu Rev Psychol 63:101-128. CrossRef Medline

Ryan L, Nadel L, Keil K, Putnam K, Schnyer D, Trouard T, Moscovitch M (2001) Hippocampal complex and retrieval of recent and very remote autobiographical memories: evidence from functional magnetic resonance imaging in neurologically intact people. Hippocampus 11:707-714. CrossRef Medline

Schnider A, Ptak R (1999) Spontaneous confabulators fail to suppress currently irrelevant memory traces. Nat Neurosci 2:677-681. CrossRef Medline

Scoville WB, Milner B (1957) Loss of recent memory after bilateral hip- pocampal lesions. J Neurol Neurosurg Psychiatry 20:11-21. CrossRef Medline

Söderlund H, Moscovitch M, Kumar N, Mandic M, Levine B (2012) As time goes by: hippocampal connectivity changes with remoteness of autobiographical memory retrieval. Hippocampus 22:670-679. CrossRef Medline

Squire LR (1992) Memory and the hippocampus: a synthesis from findings with rats, monkeys, and humans. Psychol Rev 99:195-231. CrossRef Medline

Steinvorth S, Corkin S, Halgren E (2006) Ecphory of autobiographical memories: an fMRI study of recent and remote memory retrieval. Neuroimage 30:285-298. CrossRef Medline

Summerfield JJ, Hassabis D, Maguire EA (2009) Cortical midline involvement in autobiographical memory. Neuroimage 44:1188-1200. CrossRef Medline

Svoboda E, Levine B (2009) The effects of rehearsal on the functional neuroanatomy of episodic autobiographical and semantic remembering: a functional magnetic resonance imaging study. J Neurosci 29:3073-3082. CrossRef Medline

Svoboda E, McKinnon MC, Levine B (2006) The functional neuroanatomy of autobiographical memory: a meta-analysis. Neuropsychologia 44:2189-2208. CrossRef Medline

Teyler TJ, DiScenna P (1985) The role of hippocampus in memory: a hypothesis. Neurosci Biobehav Rev 9:377-389. CrossRef Medline

Tse D, Takeuchi T, Kakeyama M, Kajii Y, Okuno H, Tohyama C, Bito H, Morris RG (2011) Schema-dependent gene activation and memory encoding in neocortex. Science 333:891-895. CrossRef Medline

Vann SD, Aggleton JP, Maguire EA (2009) What does the retrosplenial cortex do? Nat Rev Neurosci 10:792-802. CrossRef Medline

Viard A, Piolino P, Desgranges B, Chételat G, Lebreton K, Landeau B, Young A, De La Sayette V, Eustache F (2007) Hippocampal activation for autobiographical memories over the entire lifetime in healthy aged subjects: an fMRI study. Cereb Cortex 17:2453-2467. Medline

Watanabe T, Kimura HM, Hirose S, Wada H, Imai Y, Machida T, Shirouzu I, Miyashita Y, Konishi S (2012) Functional dissociation between anterior and posterior temporal cortical regions during retrieval of remote memory. J Neurosci 32:9659-9670. CrossRef Medline

Weiskopf N, Hutton C, Josephs O, Deichmann R (2006) Optimal EPI parameters for reduction of susceptibility-induced BOLD sensitivity losses: a whole-brain analysis at 3T and 1.5T. Neuroimage 33:493-504. CrossRef Medline

Weiskopf N, Sitaram R, Josephs O, Veit R, Scharnowski F, Goebel R, Birbaumer N, Deichmann R, Mathiak K (2007) Real-time functional magnetic resonance imaging: methods and applications. Magn Reson Imaging 25:989-1003. CrossRef Medline

Winocur G, Moscovitch M (2011) Memory transformation and systems consolidation. J Int Neuropsychol Soc 17:766-780. CrossRef Medline

Yushkevich PA, Piven J, Hazlett HC, Smith RG, Ho S, Gee JC, Gerig G (2006) User-guided 3D active contour segmentation of anatomical structures: significantly improved efficiency and reliability. Neuroimage 31:11161128. CrossRef Medline 